\title{
Diagnóstico por la imagen de los malos tratos infantiles.
}

Imaging diagnosis of non-accidental injury in children.

\section{Gómez de Terreros¹, I. Serrano Urbano² y MC. Martínez Martín²}

\begin{abstract}
RESUMEN
El papel de la imagen en los casos de sospecha de malos tratos no es solo identificar el grado de lesiones físicas, sino también valorar todos los hallazgos de imagen que apunten hacia diagnósticos alternativos. Se hace preciso pruebas clarificadoras que nos lleve a un diagnóstico seguro y evite por un lado errores diagnósticos y por otro mantener una situación de riesgo de nuevos episodios de maltrato de consecuencias impredecibles.

La actual oferta tecnológica del diagnóstico por imagen, exige al clínico que se enfrenta a un diagnóstico de sospecha de maltrato físico, conocer cuales son las lesiones más especificas de confirmación diagnóstica, así como cual es la técnica/as más indicada de acuerdo a la clínica y edad del paciente. Revisamos las recomendaciones actuales partiendo de nuestra experiencia.
\end{abstract}

Palabras clave: Maltrato infantil. Hallazgos radiológicos. Lesiones óseas Técnicas de imagen.

Cuad Med Forense 2006; 12(43-44):21-37

\section{ABSTRACT}

The image technology develops an important role in cases of abuse suspicion not only establishing the degree of physical harm, but also finding evidences that lead to different diagnosis. These verified evidences are required both to reach a certain diagnosis and to avoid mistakes which can perpetuate a risk situation and the arrival of new episodes of abuse with unpredictable consequences.

The present situation in the image technology diagnosis demands from the physician the identification of the most specific lesions to confirm a suspicion of abuse as well as the most suitable technology according to the symptoms and age of the patient. We review the current recommendations from our experience.

Key words: Child abuse. Radiological findings. Bone injuries. Image techniques.

Correspondencia: Dr. Ignacio Gómez de Terreros. C/ Capitán Vigueras nº 3. 1 A. 41004. Sevilla. Tf. 954414460. E-mail: terreros@us.es

1 Profesor Titular y Jefe de Servicio de Pediatría. Hospital Infantil Universitario "Virgen del Rocío". Sevilla.

2 Servicio de Radiología Pediátrica. Hospital Infantil Universitario "Virgen del Rocío". Sevilla. 


\section{INTRODUCCIÓN:}

La conceptualización de los malos tratos infantiles como entidad médica tuvo desde sus inicios la implicación de figuras de la radiología pediátrica. En 1946 el Radiólogo Pediátrico John Caffey describió un cuadro clínico en niños afectados de hematoma subdural y fracturas múltiples de origen probablemente traumático. Siete años más tarde F. Silverman reconoce por primera vez que los causantes de los traumatismos podían ser los padres por actitud negligente o descuido, cuando no por agresión deliberada. En 1957 Caffey describe las típicas fracturas del maltrato denominadas en esquina y en asa de cubeta (Figura I) y con posterioridad en 1972 introduce el término de "niño sacudido". Desde entonces muchos han sido los autores que han colaborado en la mejor catalogación radiológica de los malos tratos infantiles, sobresaliendo Swischuck, Merten y Kleinman. En I96I Henry Kempe organiza un simposio interdisciplinario en la Reunión Anual de la Academia Americana de Pediatría sobre el síndrome del niño golpeado y en 1962 el Journal of the American Medical Association publica una descripción completa del síndrome desde el punto de vista pediátrico, psiquiátrico, radiológico y legal. Su denominación "síndrome del niño apaleado" (Battered Child Syndrome) queda acuñada en la literatura médica mundial $[1,2,3]$.

En nuestro entorno destaca la figura de Antonio María López Barrio, con el que compartí, hasta su muerte en 1999, nuestra inquietud científica sobre esta entidad y sus manifestaciones radiológicas, especialmente en su contribución al diagnóstico no siempre fácil y comprometido. Su vocación docente permanece viva a través de su abundante archivo iconográfico, con aportaciones de compañeros radiólogos de toda España y que su viuda donó al Servicio de Radiología Pediátrica del Hospital Infantil Universitario "Virgen del Rocío" de Sevilla donde desarrolló toda su actividad profesional, científica e investigadora. Esperamos que este articulo sirva de vehiculo para seguir trasmitiendo sus conocimientos, soporte importante en nuestro quehacer médico, ya que el diagnóstico por imagen de los malos tratos infantiles se basa tanto en avances de la tecnología de imagen como en un mejor conocimiento científico del tema.

El papel de la imagen en los casos de sospecha de malos tratos no es solo identificar el grado de lesiones físicas cuando se han producido los malos tratos, sino también valorar todos los hallazgos de imagen que apunten hacia diagnósticos alternativos. Cuando se estudian todos los casos de malos tratos y negligencia en niños, la incidencia de las evidencias físicas documentadas mediante estudios de diagnóstico por la imagen es relativamente pequeña. En nuestra propia experiencia, un 7,5 por 100 de los estudios radiológicos fue positivo y, lo que es más importante, en un 3,7 por 100 de las exploraciones se demostraron lesiones que ni la historia clínica inicial ni la exploración física había detectado previamente fueron positivas [4]. Es importante precisar que la contribución diagnóstica por las técnicas de imagen en el maltrato infantil es sin duda importante, pero siempre valorándolas en el contexto de una historia clínica, social y tras una exploración física muy cuidadosa, y exhaustiva y considerando que el diagnóstico y seguimiento de estos niños maltratados es labor de un Equipo Multidisciplinario en el que el Radiólogo debe estar integrado y comprometido [3].

En los aspectos técnicos la AAP considera que los sistemas de imagen pediátricas de bajas dosis con fines globales proporcionan un detalle anatómico insuficiente para valorar las imágenes del esqueleto del lactante y del niño pequeño. El American College of Radiology ha publicado estándares de pruebas de imagen de la revisión del esqueleto en caso de sospecha de malos tratos. Los modernos sistemas de imagen pediátricos habitualmente utilizan cassettes de película especial e intensificadores de imágenes para minimizar la exposición. Aunque estos sistemas de bajas dosis son suficientes en las imágenes de tórax y abdomen, no consiguen lograr el contraste necesario y la resolución espacial suficiente para visualizar las sutiles lesiones metafisarias, costales y otras de alta 
especificidad que son características de los malos tratos. Según el American College of Radiology, los sistemas de imagen utilizados para la sospecha de malos tratos de lactantes deben tener una resolución espacial de al menos 10 pares de líneas por milímetro y una velocidad no superior a 200. Estos sistemas deben utilizarse sin rejilla. Pasado la lactancia, se requieren sistemas con fines generales de mayor rapidez para las regiones corporales de más grosor (es decir, cráneo, columna lumbar lateral). La radiografía digital o sin película está comenzando a sustituir a la radiografía de película en algunos centros. Los datos de que se dispone son limitados respecto a la idoneidad de esta técnica para la evaluación de lesiones esqueléticas infligidas. Esta técnica deber demostrar un rendimiento comparable a la radiografía de película de alto detalle antes de que se use rutinariamente en casos de sospecha de malos tratos infantiles. En cualquier caso, un radiólogo experimentado debe controlar el examen radiológico del esqueleto para asegurar que se han obtenido las imágenes adecuadas de alta resolución [5].

\section{RADIOLOGÍA CONVENCIONAL [3,5]:}

La "radiografía corporal" (un estudio que incluya a la totalidad del lactante o niño pequeño en una $\circ 2$ radiografías) o revisiones esqueléticas abreviadas no tienen papel en la valoración por imagen de estas anomalías óseas sutiles pero altamente específicas. El American Collage of Radiology estableció el estándar en cuanto al estudio esquelético (Tablal), el cual debe realizarse siempre en los menores de dos años dado que por debajo de esta edad las fracturas metafisarias no tienen porque impedir caminar, provocar cojera, dificultar el movimiento de las piernas o gatear sin dolor. Por encima de los cinco años la exploración esquelética de cribado está demostrado que no tiene utilidad. Los del grupo de dos a cinco años deberán explorarse según orienten los datos clínicos (5). En la revisión realizada por Worlock (6) de 35 niños con lesiones esqueléticas no accidentales y grupo control de 826 menores con lesiones accidentales, ningún niño de más de cinco años tuvo fracturas como consecuencia de una agresión y 80 por ciento de las fracturas en niños objetos de agresiones se produjeron antes de los 18 meses, destacando en numero las fracturas costales y contrastando con el grupo de lesiones accidentales en el que el 85 por ciento de las fracturas se produjeron después de los 5 años.

TABLA I: Estudio esquelético estándar.

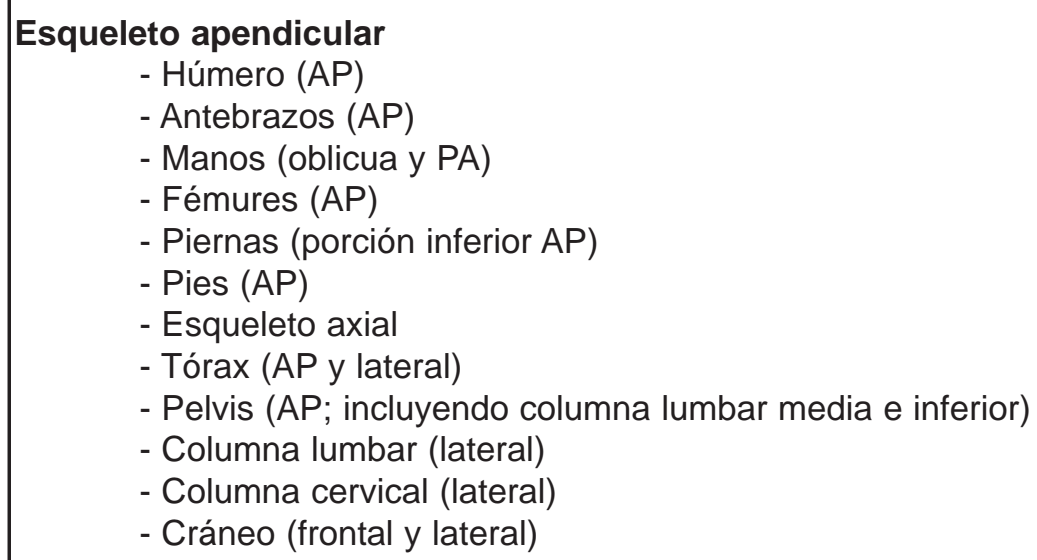

AP: anteroposterior; PA: posteroanterior. 
Respecto a las imágenes, está generalmente admitido como lesiones esqueléticas de gran especificidad diagnostica de maltrato a aquellas fracturas, a veces muy sutiles, que aparecen en la región epífiso-metafisaria en forma de luxación, arrancamiento o desplazamiento epifisario, adoptando las típicas formas de fracturas metafisarías descritas como en "asa de cubeta" o en "esquina metafisaria" y que no son ni más ni menos que imágenes distintas provocadas por la variación en la proyección radiológica de las fracturas descritas por Salter y Harris como del tipo Il; y que tienen su origen en los movimientos bruscos de estiramiento y torsión simultánea provocados al coger por las extremidades a los niños para balancearlos, golpearlos contra algún objeto o proyectarlos a distancia. López Barrio observó que estas fracturas de Salter y Harris tipo II presentan una gran variedad en su expresión radiológica que superan la denominación clásica de fracturas en esquina y en asa de cubeta, proponiendo la siguiente clasificación [3]:

Tipo I: en la que se aprecia una línea radiolúcida metafisaria correspondiente a la fractura y/o imagen en esquina y/o en asa de cubeta. Evolucionan sin deformidad metafisaria (Figura I).

Tipo II: en la que la fractura forma un bloque separado del resto del hueso, adoptando una forma en luna en cuarto menguante. Evolucionan sin o con leve deformidad metafisaria (Figura 2).

Tipo III: en la que existe un gran desplazamiento de la plataforma metafisaria junto a un mayor o menor grado de luxación articular. Evolucionan con gran deformidad metafisaria (Figuras 3, 4, 5).

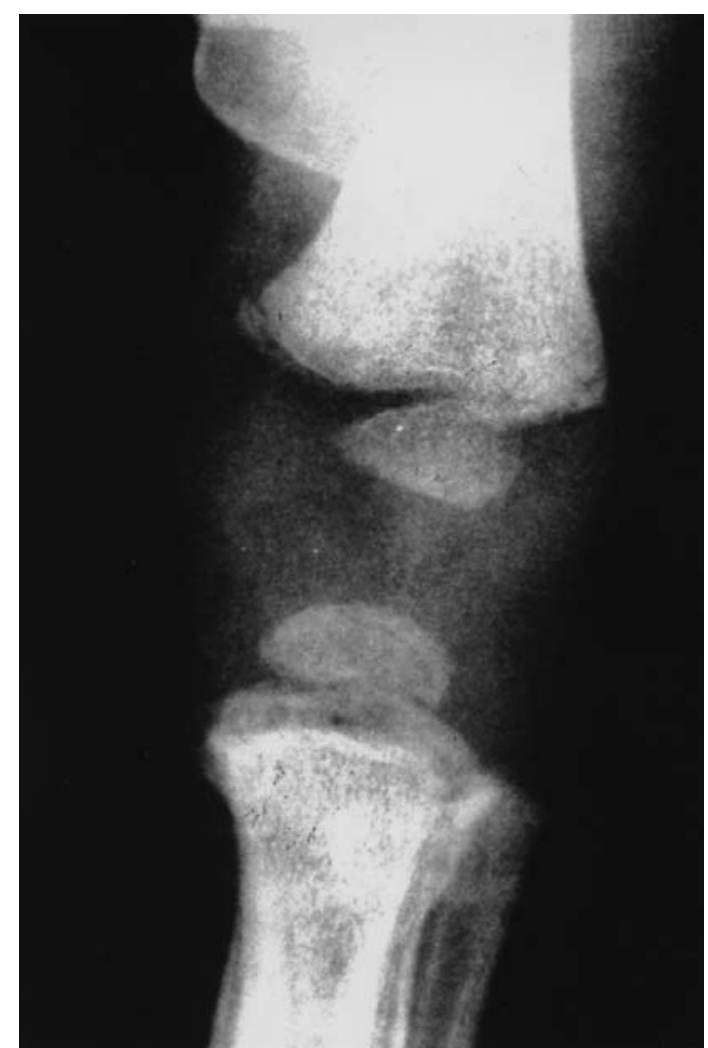

Fig. 1. Radiografia localizada de la rodilla izquierda en la que se aprecian las fracturas metafisarias "en esquina" en la metáfisis distal del fémur y la reacción subperióstica en "asa de cubeta" de la metáfisis proximal de tibia

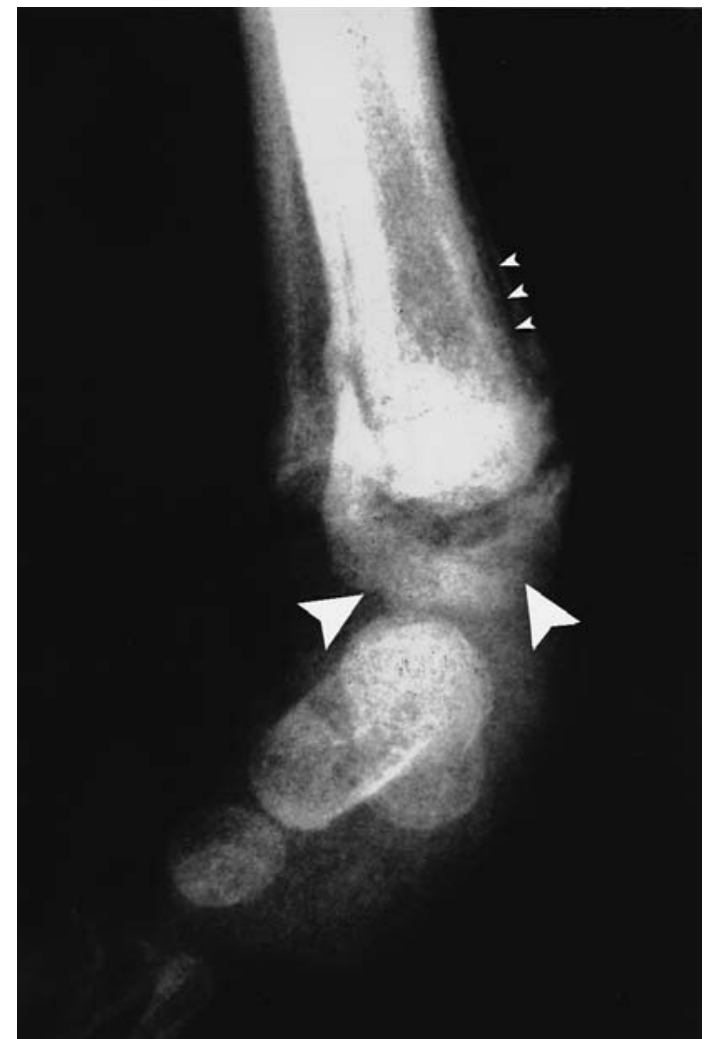

Fig. 2. Fractura Tipo II: fractura metafisaria en bloque con forma de "luna en cuarto menguante" (flechas grandes). Levantamiento perióstico tibial de tipo sólido (flechas pequeñas). 


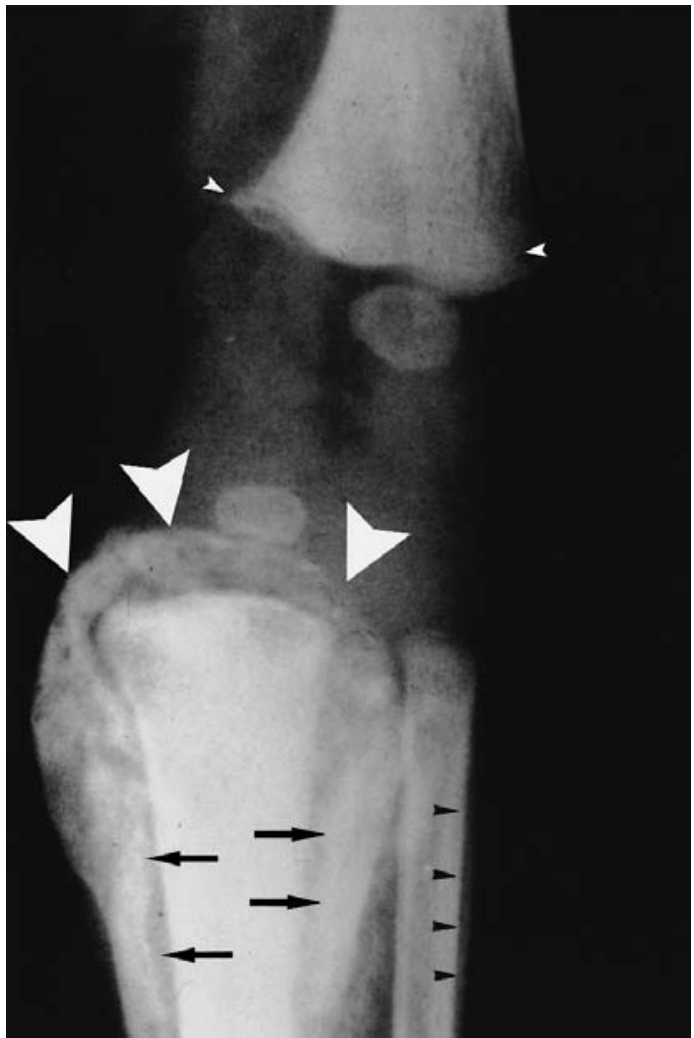

Fig. 3. Fractura Tipo III: desplazamiento metafisario proximal tibial en forma de arco (flechas blancas grandes). Luxación de la rodilla. Fractura Tipo I en la metáfisis distal del fémur (flechas blancas pequeñas). Levantamientos periósticos de tipo sólido, abigarrado en tibia (flechas negras grandes) y sutil en peroné (flechas negras pequeñas).

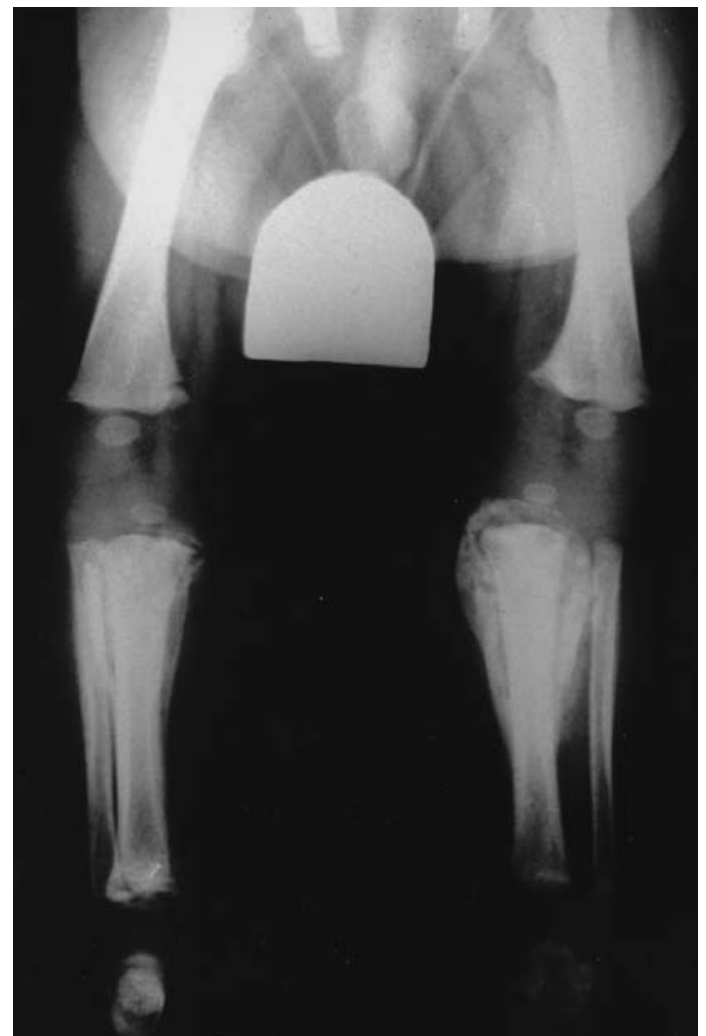

Fig. 4. Radiografía panorámica de miembros inferiores. Fracturas metafisarias Tipo I en ambos fémures. Luxación bilateral de rodillas, más evidente en el lado izquierdo. Fractura Tipo III en la metáfisis proximal de ambas tibias y Tipo II en la distal de la tibia derecha. Levantamientos periósticos de tipo sólido abigarrado en ambas tibias y sutil en el peroné izquierdo. Imagen cedida por el Dr. A Martínez Pérez del Hospital Materno-Infantil 12 de Octubre de Madrid.

La resonancia magnetica y la ecografía pueden estar indicadas cuando se sospechan separaciones epifisarias a partir de los resultados de las radiografías simples.

López Barrio destaca en los niños sometidos a maltrato físico, con mecanismo de producción consistente en la rotación del cuerpo, cogiendo al niño por las extremidades, que a los pocos días aparecían, generalmente, en ambas tibias unos levantamientos periósticos (Figura 6), de tipo sólido o laminar, que considera patognomónicos del maltrato, y que no se observan en los peronés, al estar estos protegidos por la masa muscular [7].

Igualmente, los levantamientos periósticos secundarios a hemorragias subperiósticas en otros huesos, así como las fracturas costales y los arrancamientos de la clavícula o del acromion, son bastante específicas del maltrato infantil, así como las fracturas esqueléticas que se descubren casualmente en una exploración y aquellas lesiones en las que no hay buena correlación con la historia clínica. La aparición de varias fracturas en diversos estadios evolutivos, nos debe hacer sospechar siempre malos tratos, especialmente cuando se asocian a lesiones extraesqueléticas, como tuvimos ocasión de apreciar en un caso relevante sufrido por un niño de 4 meses de edad [8]. Las fracturas 
diafisarias en espiral son más frecuentes en el maltrato que en los accidentes, siendo, en general, de localización más usual en el lado derecho debido a la mayor incidencia de individuos diestros (Figura 7).

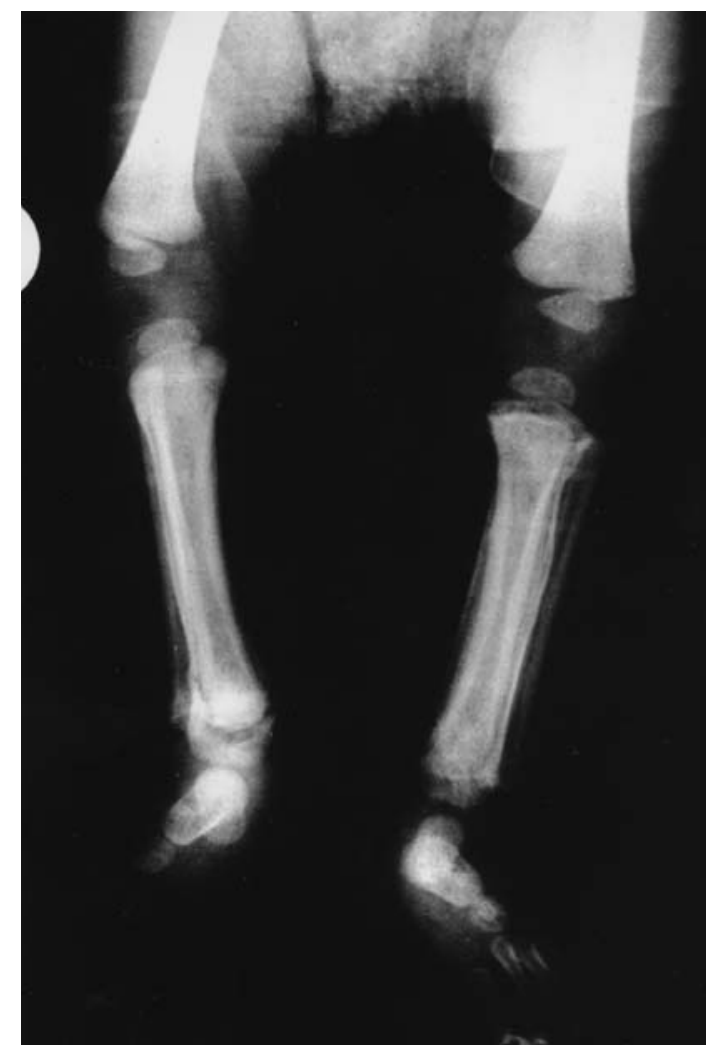

Fig. 5. Radiografía de miembros inferiores en la que se aprecian fracturas en "esquina metafisaria" en la metáfisis distal del fémur izquierdo y formación de hueso subperióstico en forma de "asa de cubeta" en la metáfisis proximal de tibia izquierda y distal de ambas tibias. Se aprecia también engrosamiento cortical en todos los huesos y reacción perióstica en ambas tibias.

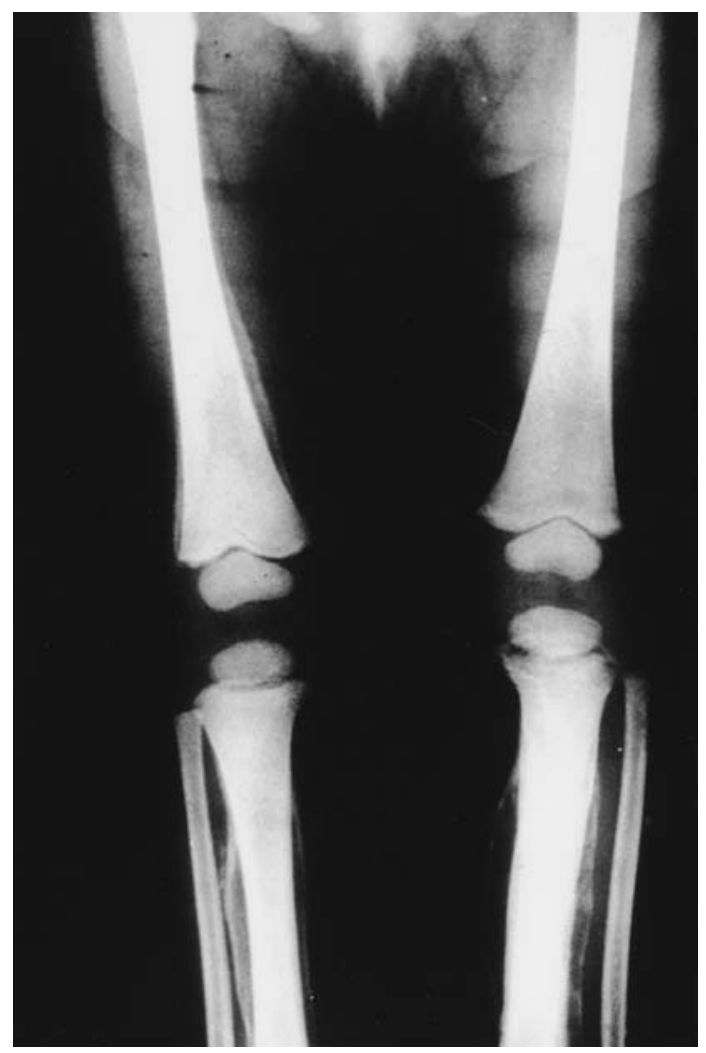

Fig.6. Radiografía de miembros inferiores visualizándose levantamientos periósticos de tipo sólido en ambas tibias y fémur derecho y ausencia de esta reacción en el peroné.

Las proyecciones anteroposterior y lateral del cráneo son obligadas incluso cuando se ha practicado una tomografía computarizada craneal porque las fracturas de cráneo que se registran en el plano axial pueden pasar desapercibidas en una tomografía computarizada. Constituye estudio fundamental en el diagnóstico del maltrato, ya que la presencia de una fractura craneal compleja, diastásica o con hundimiento, en presencia de hemorragias retinianas, asociada a otras lesiones en piel y mucosas, y/o a otras fracturas, junto a signos externos de abandono, y, sobre todo, cuando no concuerdan los hallazgos con la lesión que cuentan los padres, es prácticamente diagnóstico de maltrato infantil.

Los tipos de fracturas craneales que se pueden observar son: lineal de bordes nítidos, estrellada, con hundimiento y diastasada; esta ultima indicativa, casi siempre, de complicación intracraneal. El que una fractura de cráneo sea múltiple, bilateral o cruce las suturas, es considerada sospechosa de tener su origen en maltrato (Figura 8). Dentro del contexto general de cráneo-cara, el apreciar una fractura deformante de los huesos propios de la nariz, que configura una "nariz de boxeador". Es muy específica de malos tratos (Figura 9). 

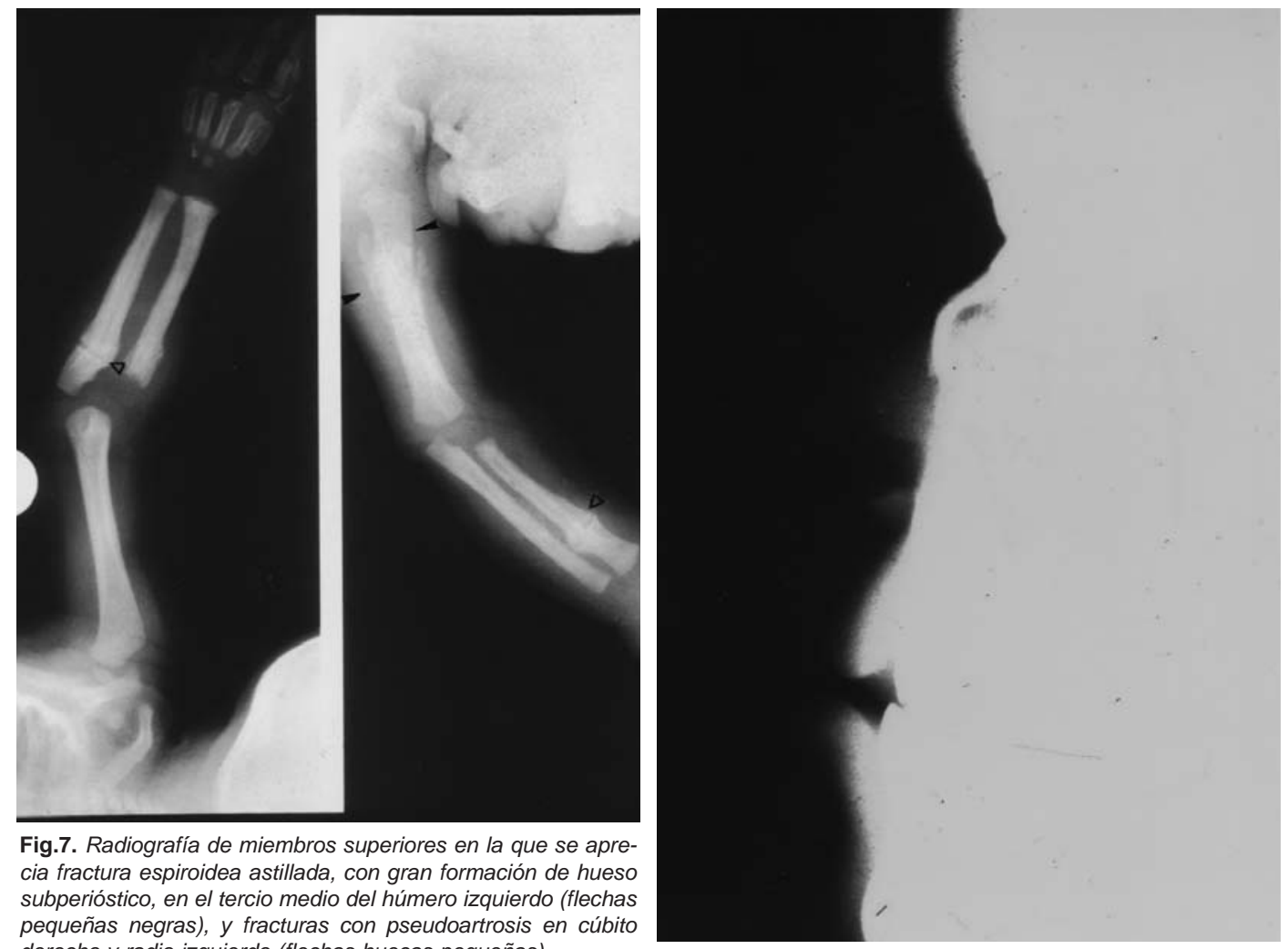

cia fractiografia de miembros superiores en la que se apre subperióstico, en el tercio medio del húmero izquierdo (flechas pequeñas negras), y fracturas con pseudoartrosis en cúbito derecho y radio izquierdo (flechas huecas pequeñas).

Fig. 9. Deformidad de los huesos propios de la nariz que inducen "nariz de boxeador".

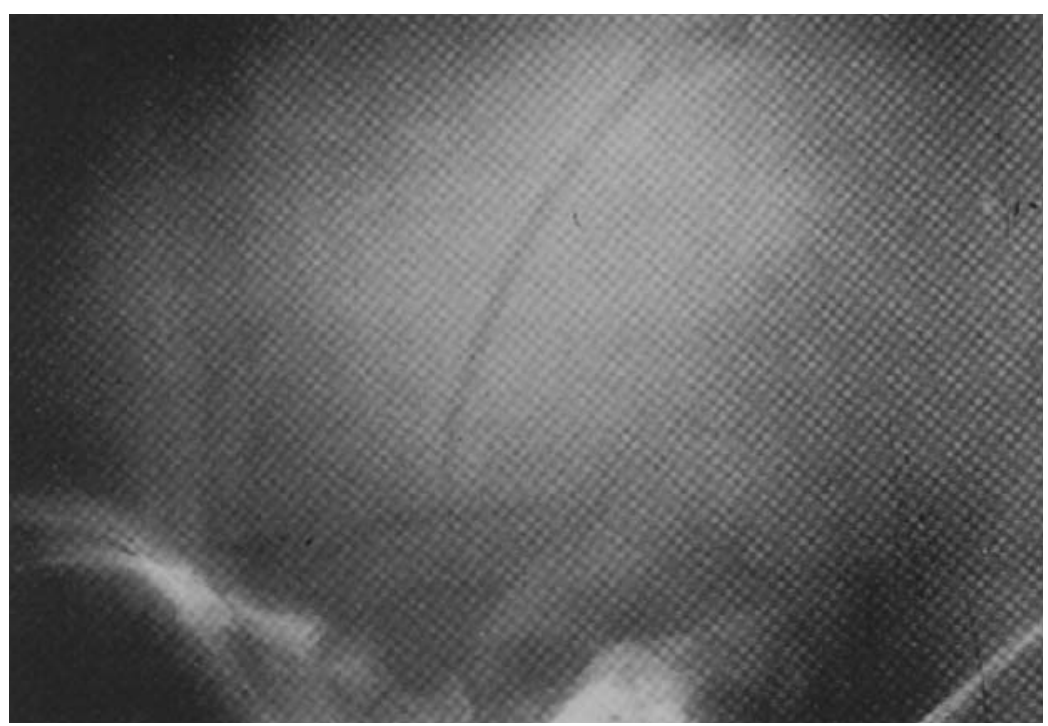

Fig.8. Radiografía lateral de cráneo mostrando fractura múltiple parieto-occipital. 
La radiografía de tórax no solo nos mostrará las fracturas costales, de localización preferente en la región postero-lateral, sino que igualmente nos pondrá de manifiesto neumotórax, contusión pulmonar (Figura 10) o derrame pleural. Para Feldman [9] las fracturas costales en los malos tratos son muy frecuentes, encontrándolas este autor en un 15 por 100 de sus casos. Para mejor demostrar las fracturas costales, a veces difíciles de visualizar, es aconsejable realizar proyecciones oblicuas.

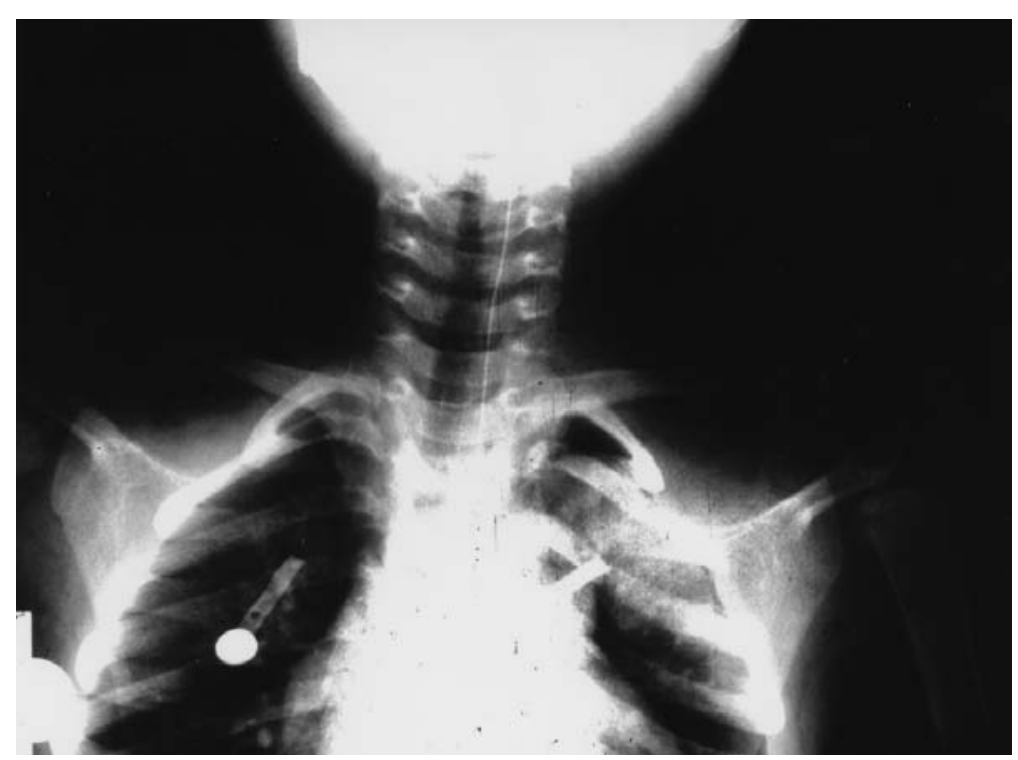

Fig. 10. Fractura del arco posterior, próxima a la articulación costo-vertebral, de la $2^{a}$ costiIla izquierda. Neumotórax apical izquierdo y condensación parenquimatosa por contusión pulmonar.

Las radiografías simples de columna vertebral son a menudo suficientes para evaluar las compresiones vertebrales y las fracturas de procesos espinosos. El aplastamiento vertebral en forma de cuña es un hallazgo bastante característico del maltrato, estando su origen en la hiperflexiónhiperextensión forzada al coger al niño por la cabeza y las piernas para golpearlo contra algún objeto. El golpe directo en esta zona puede producir, igualmente, fracturas, a veces, con luxación y lesión medular.

Las fracturas complejas de columna vertebral, pueden requerir una tomografía computarizada de cortes finos con reconstrucción multiplanar posterior. Si una fractura o subluxación puede comprometer contenidos de la columna o si los hallazgos clínicos indican lesión de la médula espinal o de las raíces, debe realizarse una resonancia magnética.

En cuanto a la revisión esquelética radiológica, datos recientes sugieren que un seguimiento a las 2 semanas del estudio inicial aumenta el rendimiento diagnóstico y debe ser considerado cuando existe una firme sospecha de malos tratos. No solo nos permitirá la determinación más precisa de la edad de las lesiones individuales, sino que la falta de cambios en los intervalos puede indicar que los hallazgos radiológicos iniciales son una variante anatómica normal o se relacionan con una displasia ósea. Por otro lado las informaciones sugieren que si un lactante gemelo está lesionado, el otro presenta riesgo y, por consiguiente, es aconsejable en estos casos la práctica de un estudio esquelético. 
La radiografía simple de abdomen tiene actualmente, una utilidad muy cuestionada, quedando limitada su práctica en el niño, en la clínica diaria, a casos de abdomen agudo, palpación de masas, localización de cuerpos extraños, calcificaciones y litiasis, y en casos de abdómenes prominentes. En el maltrato se suele observar abdómenes con abundante meteorismo originado por el llanto continuo, modificaciones del patrón aéreo en relación con neumoperitoneo, sangrado peritoneal por contusión de las asas intestinales y del meso, hematoma duodenal o pseudoquiste de páncreas, a la vez que se puede localizar cuerpos extraños introducidos por los agresores. En estos casos es recomendable realizar una radiografía panorámica de tórax-abdomen, en doble proyección. Igualmente, la radiografía de abdomen debe poner de manifiesto las grandes fracturas pélvicas.

Los estudios baritados son útiles para el diagnóstico, afortunadamente no muy frecuente, del hematoma duodenal (Figura I I), y para demostrar que el escaso desarrollo del niño y sus vómitos no están relacionados con un reflujo gastro-esofágico. Excepcionalmente hay que recurrir al enema opaco para demostrar lesiones del recto o del colon, relacionadas con el maltrato, aunque cada día se describen más agresiones mediante la administración, por cualquier vía, de objetos y/o sustancias lesivas. En tal sentido vivimos la experiencia de una presentación inusual de Síndrome de Munchausen por poderes a través de la ingestión reiterada de cuerpos extraños (dos pendientes, posible botón no confirmado, tornillo de $5 \mathrm{cms}$ y dos agujas de costura, producido por una madre joven de 22 años en una lactante de 10 meses y que se muestra en el capítulo dedicado al Munchausen en esta monografía sobre el maltrato infantil. [ 10$]$.

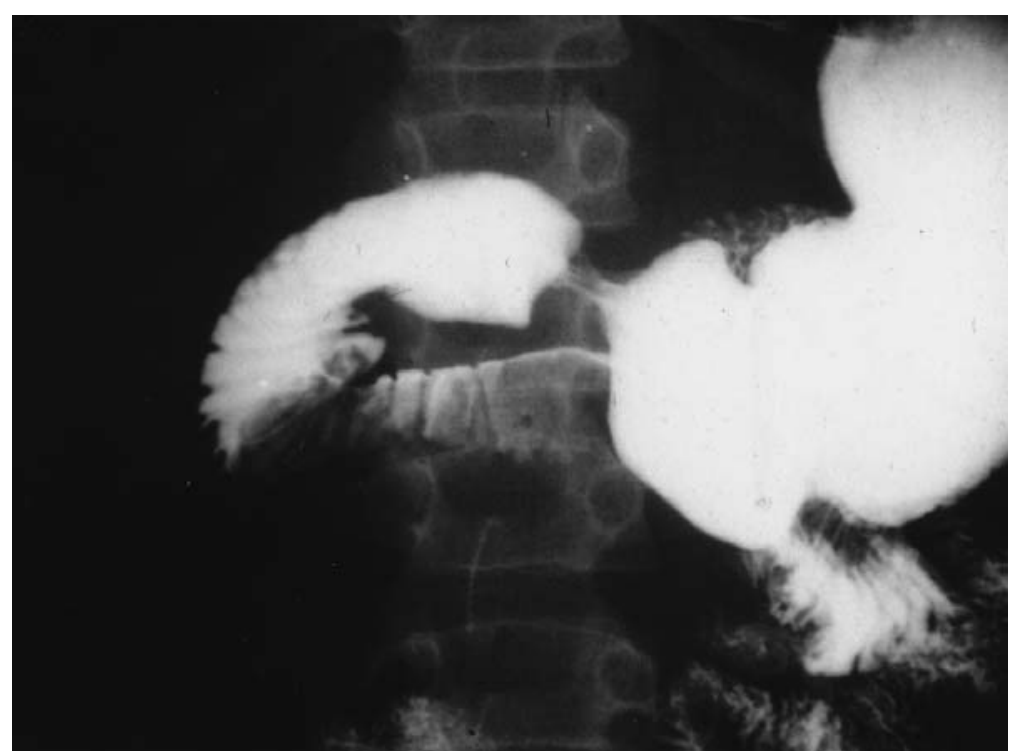

Fig. 11. Hematoma duodenal que provoca compresión extrínseca de la $2^{a}$ y $3^{a}$ porción del duodeno.

Las exploraciones con contrastes yodados tienen una utilidad muy limitada en el maltrato, dado que por este motivo, la rotura renal, es rara. Nosotros hemos observado, ecográficamente, una contusión renal en un lactante maltratado con hematuria, que evolucionó favorablemente. La presencia de hemoglobinuria y mioglobinuria deben motivar un trato de cautela en el uso de contrastes yodados, tanto en la urografía intravenosa como en la tomografía computada. 


\section{LA GAMMAGRAFÍA ÓSEA:}

La Gammagrafía ósea es otra técnica de imagen de utilidad diagnóstica en el maltrato, siendo su aplicación preferente para demostrar cambios óseos tan solo unas horas después de la agresión y cuando aún estas no son visibles en la radiografía esquelética, así como para la detección de lesiones esqueléticas que pueden pasar desapercibidas en las radiografías. Entre las lesiones que son mejor detectadas por la gammagrafía están las que afectan a los tejidos blandos y aquellas localizadas en áreas óseas complejas como la pelvis [I I ]. A pesar de ello las radiografías siguen siendo el método de elección para la valoración de las lesiones óseas, ya que pueden proporcionar datos que nunca aporta la gammagrafía, como es la de diferenciar las fracturas de los tumores o de las osteoartritis, a la vez que realizan un estudio cronológico del callo de fractura. No obstante, dado que tanto las radiografías del esqueleto como la gammagrafia ósea tienen un elevado número de falsos negativos, cuando alguna de estas exploraciones sea negativa, inicialmente, y sin embargo existan signos claros de malos tratos, deberán practicarse ambas técnicas para asegurar una mayor probabilidad de establecer el diagnóstico de fractura. Puede ser coadyuvante a la evaluación esquelética radiológica en casos seleccionados, particularmente en niños mayores de un año [3].

La gammagrafía parece tener una mayor sensibilidad en la detección de fracturas costales, fracturas diafisarias sutiles y áreas de elevación perióstica precoz. Sin embargo, los datos de los que se dispone son limitados respecto a la sensibilidad de la gammagrafía en las lesiones metafisarias clásicas de los malos tratos, particularmente cuando las lesiones son bilaterales, así como en lesiones sutiles de la columna, características que comportan una elevada especificidad de malos tratos en los lactantes. Si se realiza gammagrafía ósea como estudio inicial, deben evaluarse todas las áreas positivas mediante radiografías, y como la gammagrafía no es sensible en la detección de lesiones craneales, deben realizarse radiografías de cráneo en al menos dos proyecciones de manera suplementaria [5].

En consecuencia, la serie esquelética y la gammagrafía ósea son pruebas complementarias en el estudio de niños que han sufrido abuso físico, debiéndose llevarse a cabo la gammagrafía para asegurar el diagnóstico, en aquellos casos de sospecha de maltrato en que no se objetivan lesiones óseas en la serie esquelética [I I].

\section{ECOGRAFÍA, TOMOGRAFÍA COMPUTADA Y RESONANCIA MAGNÉTICA:}

López Barrio las agrupa, al considerar que en el estudio del cerebro, ocupan un lugar escalonado dentro del algoritmo diagnóstico de lesión intracraneal.

El daño cerebral está reconocido como la causa de mayor mortalidad y morbilidad en el Síndrome del niño maltratado. La observación de una lesión intracraneal en un lactante, en ausencia de antecedentes de un traumatismo importante, constituye una base suficiente para una investigación de malos tratos. Para Saulsbury [12], si al sangrado intracraneal (hematoma subdural), en el que se descartan anomalías vasculares y diátesis hemorrágicas, se añade la existencia de una fractura, esto confirma el diagnóstico de niño maltratado. Se puede afirmar que las lesiones cutaneomucosas, junto a las osteoarticulares y oculares (hemorragias retinianas) son las más indicativas de malos tratos. De ahí la importancia de efectuar siempre el estudio del fondo de ojo ante una sospecha de maltrato. En cuanto a las lesiones cutáneas asociadas, tener en cuenta que si son bilaterales casi siempre serán provocadas y en cuanto a las quemaduras pueden ser diferenciadas por las características de forma, profundidad, delimitación de bordes, simetría y localización, valorándose en ambas las circunstancias asociadas, como pueden ser retraso en la solicitud de asistencia o la existencia de factores predisponentes de riesgo. 
La caída accidental provoca excepcionalmente lesiones intracraneales. Kravitz [13] solo encuentra un hematoma subdural en 330 caídas accidentales de niños de menos de dos años. Esto es debido a la gran flexibilidad de la bóveda craneal, a la mayor plasticidad cerebral, a la gran cantidad de líquido cefalorraquídeo que rodea al cerebro y a la vasorreactividad de la circulación del cerebro pediátrico. Helfer [14] no encontró lesiones graves o que pusieran en peligro la vida del niño en 246 caídas de la cama o de la camilla de exploración del hospital, en niños menores de cinco años. Parece claro que solo los accidentes de tráfico pueden producir lesiones similares a las descritas en el Síndrome del niño maltratado.

Las lesiones características que pueden concurrir con un traumatismo craneoencefálico por maltrato son, la alopecia por tracción, el hematoma subgaleal usualmente en la base de una trenza como consecuencia del tirón de la misma y las equímosis periorbitarias, que si bien puede ser unilaterales o bilaterales, las unilaterales suelen tener origen accidental.

Las fuerzas de alta energía asociadas a un impacto o a sacudidas violentas dan lugar a una variedad de lesiones del sistema nervioso central que, hoy día, pueden detectarse mediante las técnicas modernas de neuroimagen. La evolución de estas lesiones, así como los procesos que aparecen secundariamente a la agresión original, a menudo se hacen evidentes en estudios seriados de imagen.

Las lesiones cerebrales que se pueden encontrar en el maltrato infantil las describe Merten [15] en dos grupos, ya sean agudas o crónicas. En las situaciones de cuidados agudos, los esfuerzos deben ir dirigidos a la detección rápida de procesos tratables. Los estudios posteriores se dirigen a delinear de forma más completa todas las anomalías, determinando la cronología de las lesiones y controlando su evolución. La estrategia debe ir dirigida a la detección de cualquier secuela intracraneal de malos tratos o negligencia con una completa caracterización de la extensión y la antigüedad de las alteraciones.

Dentro de las agudas hay que distinguir aquellas de localización extracerebral, como son: la hemorragia subdural -la más frecuente- (Figuras 12 y 13) la hemorragia subaracnoidea y la hemorragia epidural.

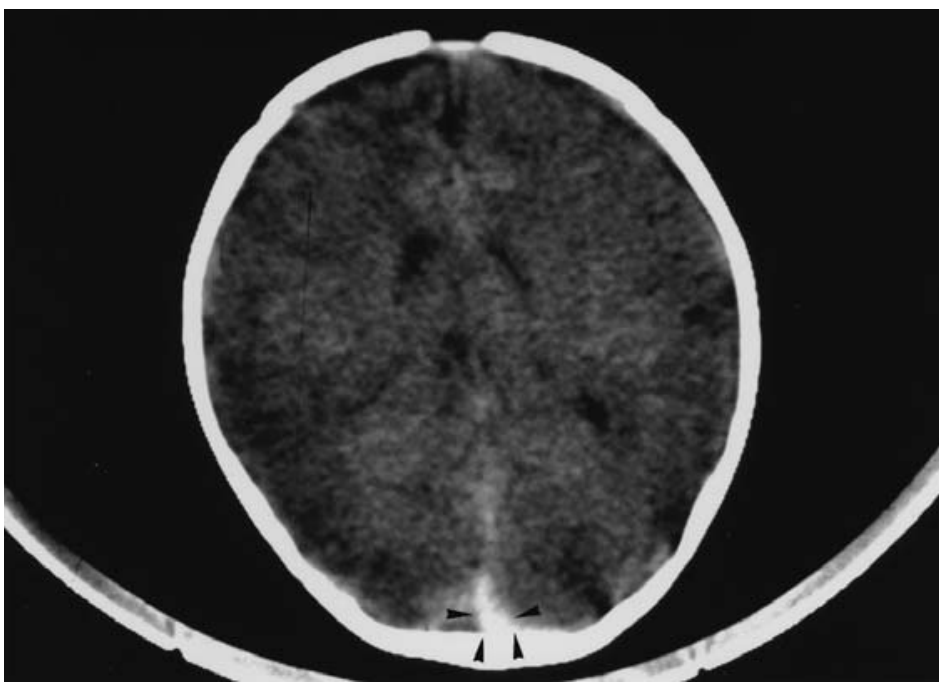

Fig.12. Tomografía computarizada: pequeña hemorragia subdural que penetra en cisura interhemisférica (flechas negras). 


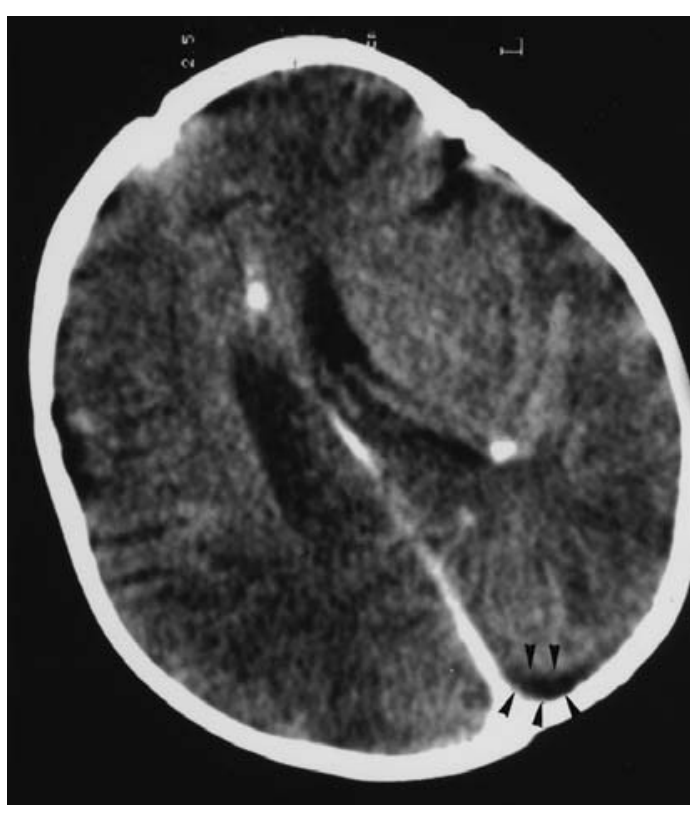

Fig.13. Tomografía computarizada: pequeño higroma subdural (flechas negras) evolución de la hemorragia de la Figura 12.

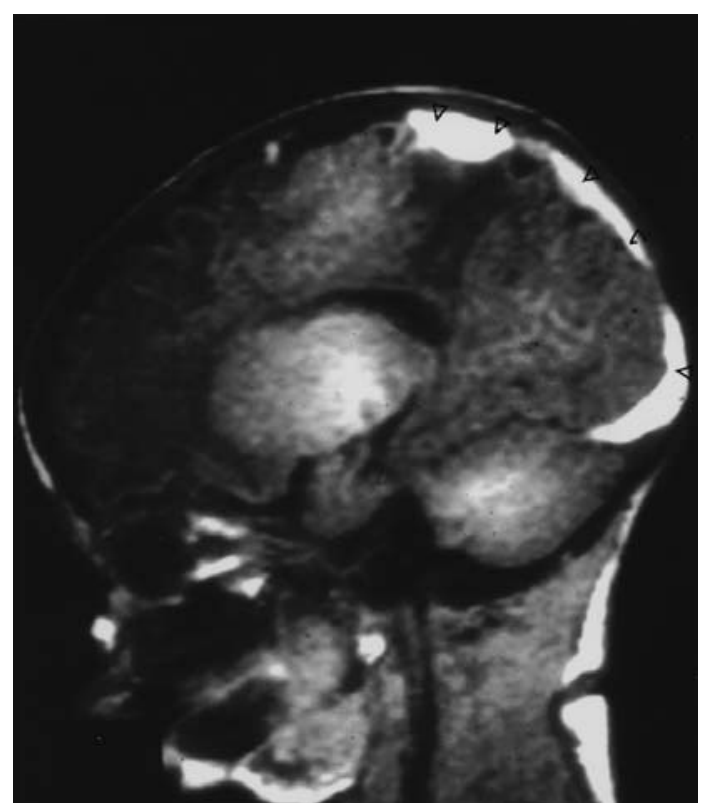

Fig.14. Resonancia Magnética con imagen potenciada en TI que pone de manifiesto una hemorragia subdural en un niño sacudido (flechas huecas pequeñas).

Imagen cedida por el Dr. Herrera Saval del Hospital Son Dureta de Palma de Mallorca.

El hematoma subdural puede presentarse con o sin fracturas de cráneo y con o sin señales externas de traumatismo. En el caso de golpes violentos, suele asociarse a fracturas craneales, lo que no ocurre cuando el traumatismo es por sacudimiento (Figura 14). La causa más común de hemorragia subdural infantil es la rotura de una o más de las delicadas venas corticales superiores que van de la corteza cerebral hacia los senos venosos, siendo el mecanismo de lesión, bien una sola aceleración-desaceleración debido a un objeto pesado móvil que incide sobre la cabeza o bien es la cabeza la que es impulsada contra una masa estacionaria. Múltiples aplicaciones de fuerza, provocan incremento de presión en las venas de unión y consecuente rotura vascular. Rotura vascular que también puede producirse sin violencia directa, como ha quedado descrito en los movimientos de aceleración-desaceleración provocados al sacudir la cabeza del niño pequeño. La asociación entre hematoma subdural y alteraciones anormales de los huesos largos incluyendo fracturas múltiples de extremidades fue mencionado en los antecedentes históricos, sin olvidar posibles asociaciones como pueden ser fracturas de costillas, desprendimientos epifisarios, y lesiones cutáneas, entre otras [16].

Dentro del cerebro podemos encontrarnos con un edema difuso o con un hematoma parenquimatoso (Figuras 15, 16 y 17), y dentro del sistema ventricular se puede producir una hemorragia, ya sea aislada o asociada a los diversos tipos referidos previamente (Figura I8). Cuando la lesión intracraneal es de evolución crónica podemos hallar un higroma subdural, una encefalomalacia focal, una atrofia cerebral generalizada, una ventriculomegalia o una porencefalia (Figuras 19, 20 y 21).

Como regla general, hoy día se admite que en todo niño con fontanela abierta la primera exploración a realizar, ante la más leve sospecha de lesión intracraneal, es una Ecografía cerebral; ahora bien, en el caso concreto de maltrato infantil esta exploración solo es un paso inicial, al que 
debe seguir lo antes posible una exploración con Tomografía computada y, si se dispone, de una exploración con Resonancia magnética. Su papel limitado pero importante, permite la valoración de las consecuencias a corto y largo plazo de las lesiones craneales infligidas. Con esta técnica se pueden demostrar los desgarros de la sustancia blanca subcortical en las regiones frontal y parasagital parietal anterior. Estas lesiones quedan menos definidas mediante tomografía computarizada y la ecografía tiene la ventaja de ser una técnica a pie de cama. Como la ecografía diferencia fiablemente las colecciones subdurales de la convexidad de las subaracnoideas, es particularmente útil en los lactantes con macrocefalia o cualquier niño con colecciones grandes en la convexidad cerebral demostradas por tomografía computarizada. Como la ecografía es insensible en la detección de pequeños hematomas subdurales agudos, particularmente en la fisura interhemisférica, y muchas otras lesiones intracraneales agudas, deberá realizarse en conjunción con la tomografía computarizada, la resonancia magnética o ambas.

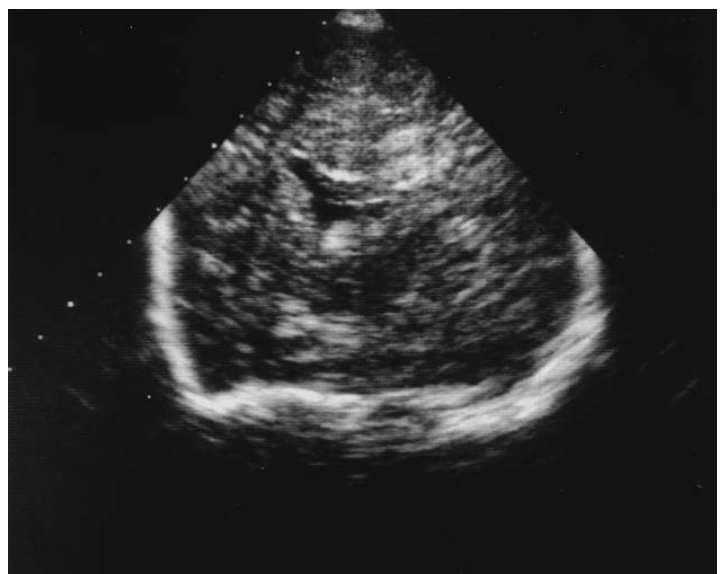

Fig.15. Ecografía cerebral transfontanelar. Corte coronal poniendo de manifiesto un hematoma parenquimatoso cerebral que oblitera el asta frontal derecha.

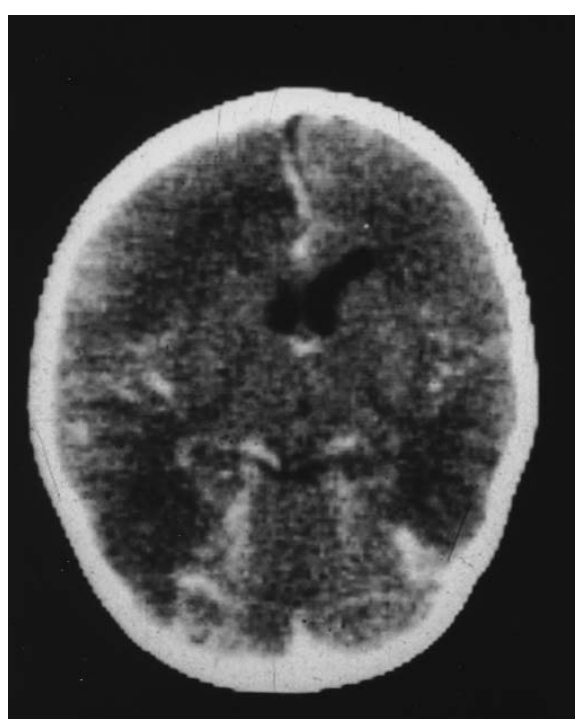

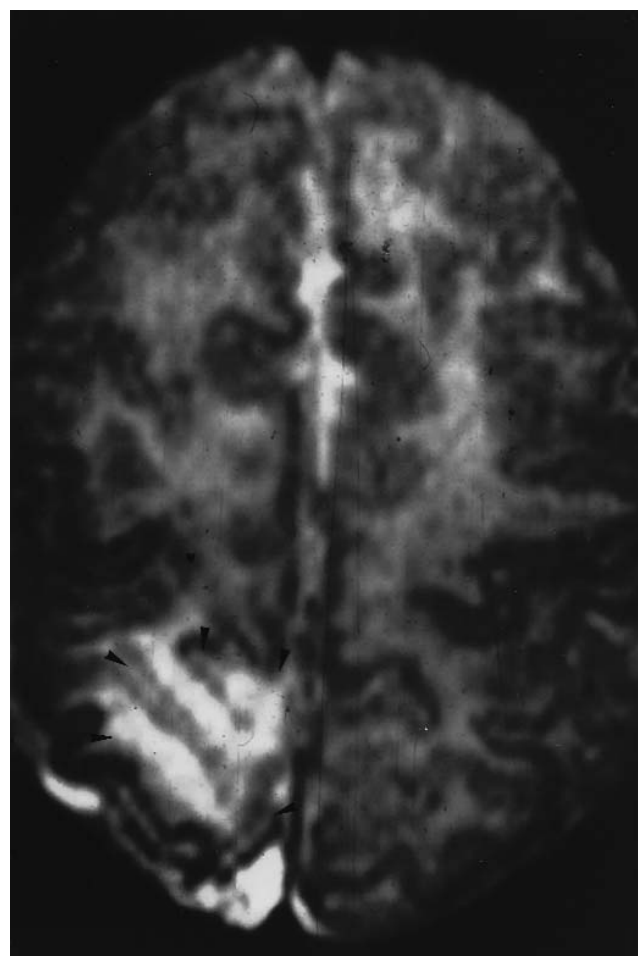

Fig.17. Resonancia Magnética con imagen potenciada en T2 en la que se aprecia un hematoma parenquimatoso cerebral (flechas negras).

Imagen cedida por el Dr. Herrera Saval del Hospital Son Dureta de Palma de Mallorca.

Fig.16. Tomografía Computarizada del mismo niño que la figura 15 mostrando obliteración del asta frontal derecha. El hematoma no se aprecia por estar en fase de isodensidad. Imágenes blancas serpentiginosas periféricas motivadas por hemorragia subaracnoidea. 


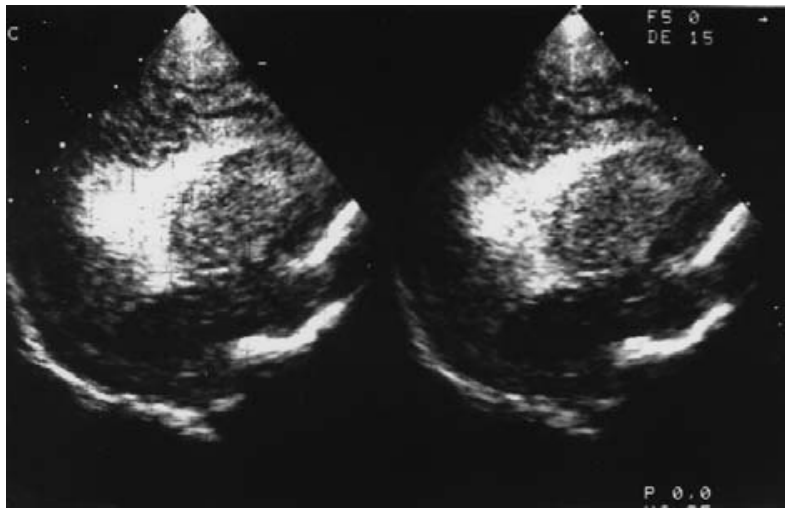

Fig. 18. Ecografía transfontanelar. Cortes sagitales paramediales izquierdos mostrando hemorragia parenquimatosa e intraventricular izquierdas.

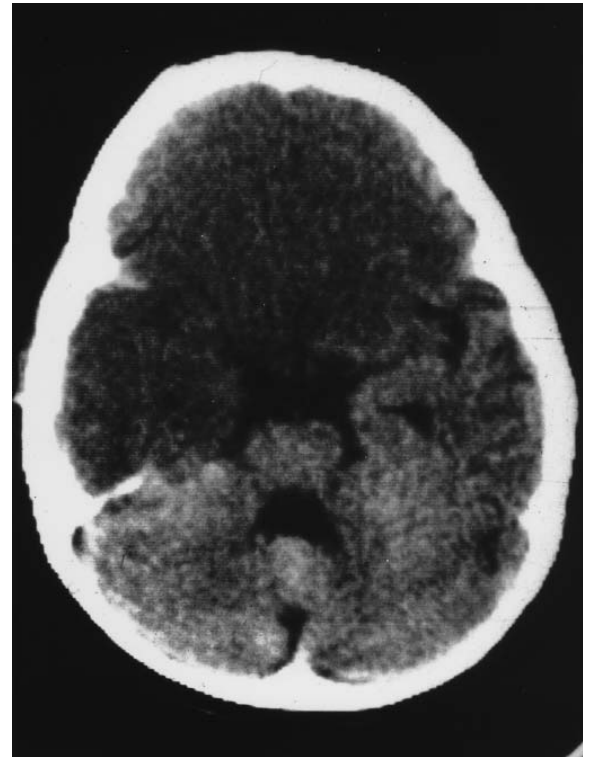

Fig. 19. Tomografía Computarizada que pone de manifiesto una encefalomalacia del territorio de las arterias carótidas internas tras intento de estrangulación. El tejido cerebral irrigado por las arterias cerebrales posteriores presenta una densidad cerebral normal.

Imagen cedida por los doctores V Pérez Candela y J Calvo Rosales del Hospital Materno-Infantil de Las Palmas de Gran Canaria.

Fig. 21. Ecografía cerebral transfontanelar. Cortes coronal derecho y sagital izquierdo en los que se evidencia una cavidad porencefálica (flechas negras pequeñas) y una franca dilatación de todo el sistema ventricular. La exploración corresponde al control evolutivo del niño de las Figuras 15 y 16.

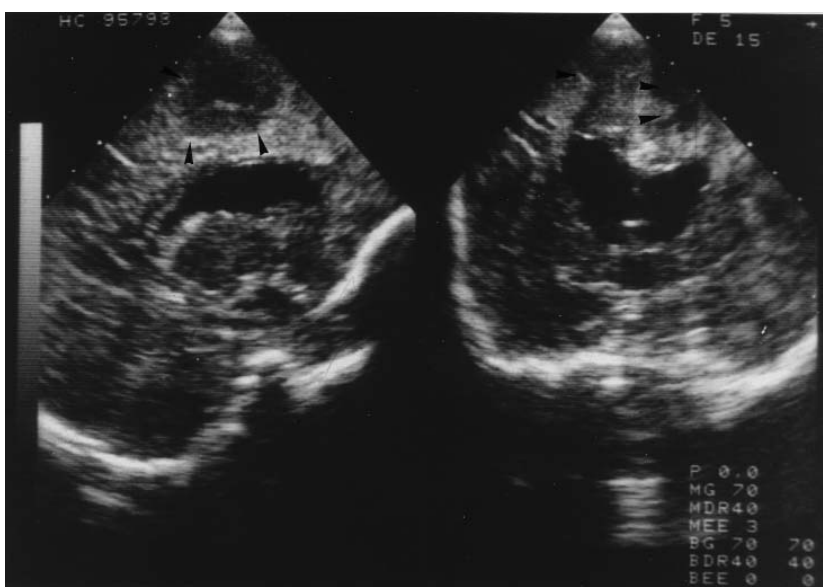


Aunque Jaspan [17] aporta datos sobre la gran utilidad de la Ecografía de alta resolución en el diagnóstico de las lesiones intracraneales, secundarias al maltrato, y aunque se sabe que la EcoDoppler es bastante fiable en el diagnóstico de los trastornos vasculares cerebrales, López Barrio insiste en que el diagnóstico de precisión de las lesiones intracraneales del maltrato infantil, son patrimonio, hoy día, de la Tomografía computada y de la Resonancia magnética.

Está bien establecido que la Tomografía computada solo es superior a la Resonancia magnética en la detección de la hemorragia subaracnoidea y en la valoración de las lesiones de la bóveda craneal, siempre que estas no tengan una disposición axial. A pesar de esto, en la fase aguda del proceso siempre es más rápida y operativa, a la vez que más disponible, la exploración con Tomografía computada. Las fracturas faciales y craneales asociadas también pueden diagnosticarse mediante el uso de ventanas óseas adecuadas.

La Resonancia magnética es la mejor modalidad para valorar globalmente la presencia de lesiones intracraneales, incluyendo colecciones extraaxiales, hemorragias intraparenquimatosas, contusiones, lesiones por desgarro y edema cerebral. Las imágenes deben realizarse con secuencias TI y T2 con secuencias de recuperación-inversión o densidad-protón para diferenciar las colecciones de líquido cefalorraquídeo de otras lesiones que contengan agua. Las secuencias gradiente-eco deben ser incluidas para detectar hemorragia o mineralización no demostrable mediante otras técnicas de Resonancia magnética. Aunque el tipo específico y el orden de secuencias de pulso pueden variar, la prueba debe realizarse al menos en los planos axial y coronal. Como la resonancia magnética puede no conseguir detectar hemorragias subaracnoideas o subdurales agudas, su uso debe ser retrasado 5-7 días en niños muy afectados. La prueba de resonancia por difusión es una técnica nueva y valiosa en la evaluación de ictus y probablemente tendrá un papel en la evaluación de lesiones cerebrales infligidas. Los niños maltratados pueden no presentar signos y síntomas neurológicos, a pesar de la presencia de importantes lesiones en el sistema nervioso central. La resonancia magnética ofrece la mayor sensibilidad y especificidad en el diagnóstico de lesiones subagudas y crónicas, y debe ser considerada siempre que se identifiquen lesiones esqueléticas asociadas a palizas o impactos [5].

Así pues una vez superada la fase aguda siempre se deberá hacer una exploración con resonancia magnética, por los siguientes motivos: I) que esta es una exploración más sensible en el seguimiento y caracterización de las lesiones parenquimatosas, a la vez que tiene un valor predictivo en la evolución clínica del paciente; 2) que es más sensible que la Tomografía computada en la identificación y caracterización de las secuelas neurológicas; 3) que demuestra mejor las alteraciones crónicas del sistema nervioso central; 4) que puede determinar el tiempo de evolución de los diversos tipos de sangrado; 5) que puede demostrar de forma precoz lesiones en la que los hallazgos clínicos no queden bien explicados por la Tomografía computada; 6) que aprecia muy bien los hematomas subdurales de la convexidad, los hematomas corticales, el edema cerebral y las lesiones de la sustancia blanca [3].

Para el estudio de la "lesión torácica y abdominal se deben aplicar inicialmente protocolos diagnósticos similares a los utilizados para una lesión de tipo accidental. Las radiografías de tórax, abdomen y columna cervical se realizan en la valoración inicial. Ante lesión grave de tórax o de abdomen sin un mecanismo conocido u observado, deberá tenerse muy presente la posibilidad de maltrato.

En el tórax, pueden observarse contusiones pulmonares, neumotórax, derrames plurales, fracturas costales, lesiones vasculares o traqueobronquiales. Rubin describe dos casos de edema pulmonar en niños maltratados, uno después de un ahogamiento confesado y otro después de un traumatismo craneal provocado [18]. 
Teniendo en cuenta que las lesiones tóraco-abdominales son especialmente graves en el maltrato infantil, una vez realizadas las exploraciones radiográficas simples deberá procederse a la realización de una Ecografia y/o Tomografía computada, que nos pueden poner de manifiesto los siguientes hallazgos: hematoma duodenal intramural, pseudoquiste de pancreas o una pancreatitis hemorrágica. Ruptura gástrica o duodenal, yeyunal, ileal o cólica. Hematoma yeyunal, ileal o retroperitoneal. Desgarro mesentérico y/o hepático, ruptura del colédoco, estenosis ileal, hemoperitoneo o ascitis quilosa postraumatica. Contusión esplénica y/o renal (rara), y fracturas de costillas, clavículas, esternón, acromion y escápula. La presencia de lesiones toracoabdominales asociadas a fracturas costales aumenta la sospecha de malos tratos infantiles. (Figura 22 y 23).

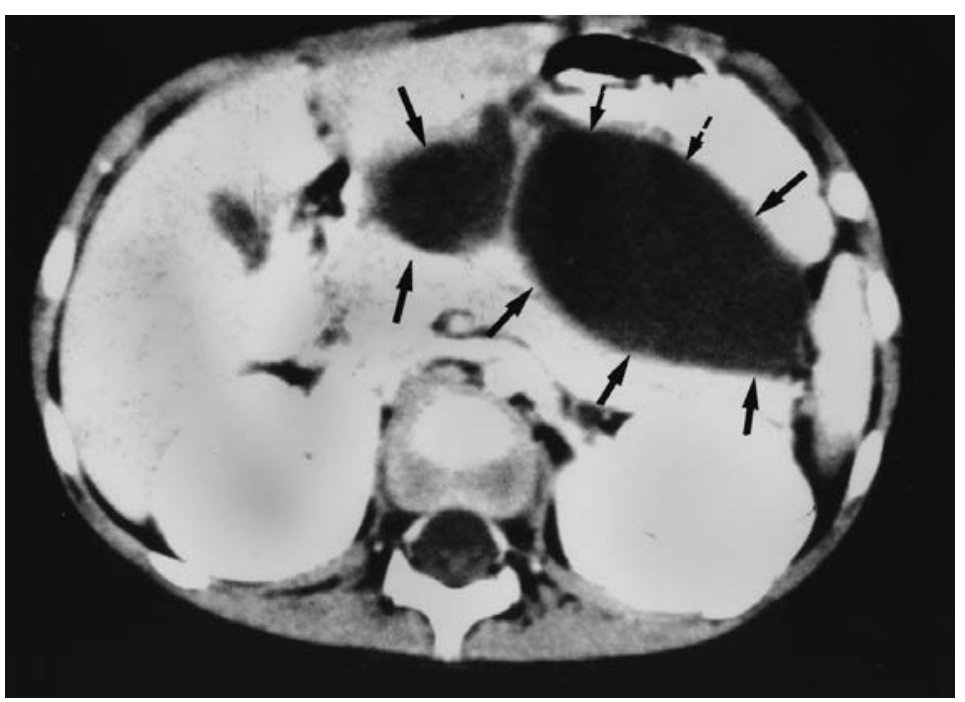

Fig. 22. Tomografía Computarizada en la que se aprecia un gran pseudoquiste de páncreas (flechas negras).

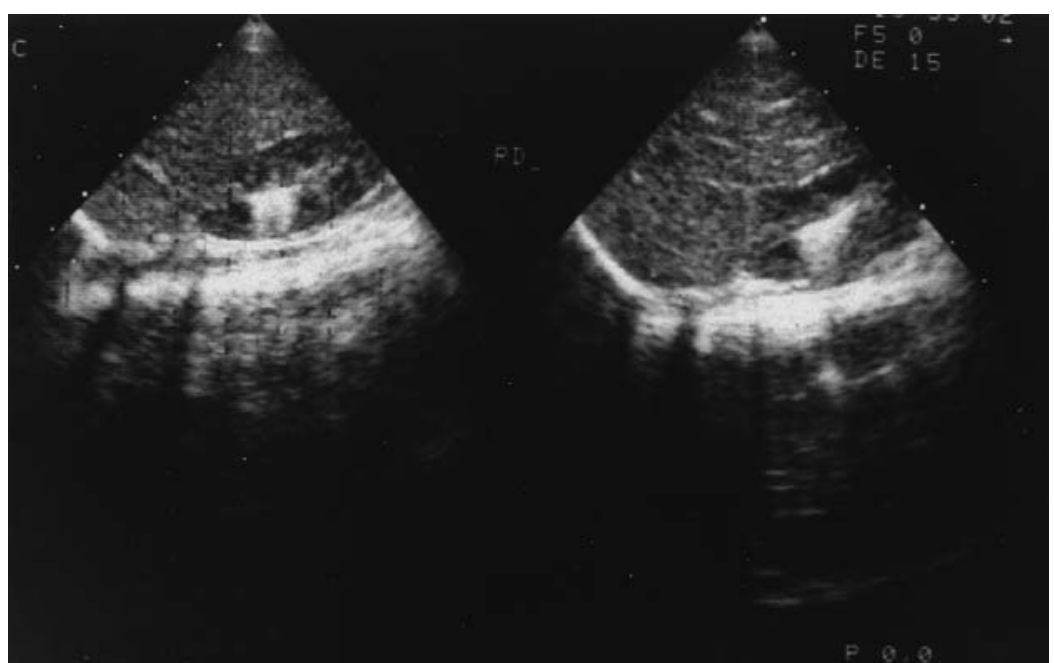

Fig. 23. Ecografía abdominal. Corte longitudinal renal derecho en el que se aprecia una hemorragia parenquimatosa renal. 
En este tipo de lesiones la ecografía la consideramos igualmente como un método de estudio inicial para desbrozar diagnósticos en aquellos casos en los que la clínica no sea muy concluyente, especialmente en niños menores de un año. En el tórax y en el abdomen la Resonancia magnética no ofrece mejores hallazgos que los que actualmente proporciona la Tomografia computada, salvo en el caso de fracturas vertebrales en las que sea importante valorar la posible lesión medular, como ya se ha comentado. Igualmente, la Resonancia magnética se ha mostrado muy precisa en el estudio de las posibles lesiones articulares de los malos tratos acaecido en niños mayores.

\section{BIBLIOGRAFÍA:}

I. Gómez de Terreros I: Los profesionales de la salud ante el maltrato infantil. $2^{\text {a }}$ ed. Editorial Comares. Granada, 1997.

2. Gómez de Terreros I. Maltrato y abandono. En: Cruz M. Tratado de Pediatría. 9a ed. Madrid: Ediciones Ergon, 2006; p. 2096-2106

3. López Barrios AM. Hallazgos radiológicos en el maltrato. En: García Caballero C, González Meneses A. Tratado de Pediatría Social. Editorial Díaz de Santos. Madrid, 2000. pp 709-721.

4. Millán Miralles L, López Barrio A M, Malo Aragón JM, Gómez de Terreros I: Análisis de nuestros hallazgos radiológicos en el maltrato infantil. Vox Paediat. 1995; 3 (I): 165-179.

5. American Academy of Pediatrics. Section on Radiology: Diagnóstico por la imagen de los malos tratos infantiles. Pediatrics (ed esp). 2000; 49 (6): 76-80.

6. Worlock P, Stower M, Barbor P: Estudio comparativo de las fracturas accidentales y no accidentales en los niños. Br Med J (ed esp). 1987; II: 26-30.

7. López Barrio AM, Pérez Candela V, Martínez Pérez A, Malo Aragón JM, Curto de la Mano A, Calvo Rosales J, Gómez de Terreros I: Levantamiento perióstico tibial: signo definitorio del maltrato infantil. Cuad Med For. 1997; 10: 37-47.

8. Lirola Cruz MJ, López Barrio AM, Malo JM y Gómez de Terreros I: Análisis de los hallazgos radiológicos en un caso relevante de maltrato infantil. Bienestar y Protección Infantil. 1996; 2:61-66.

9. Feldman KW, Brewer DK: Malos tratos en los niños, reanimación cardiaca y fracturas costales. Pediatrics (ed esp). 1984; 17:64-67.
10. G6mez de Terreros I, G6mez de Terreros M, Serrano M, Jiménez AV, Sánchez M, Salazar N, López Barrio A M y Malo JM.: Ingestión reiterada de cuerpos extraños. Forma inusual de presentación del síndrome de Munchausen por poderes. Child Abuse and Neglect. 1996; 20:613-620. II. Curcoy Barcenilla Al, Trenchs Sainz de la Maza V, Pou Fernández J. Utilidad de la gammagrafía ósea en el diagnóstico diferencial del maltrato infantil. An Pediatr. 2006; 65(I):83-84.

12. Saulsbury FT, Alford BA: Intracranial bleeding from child abuse: The value of skull radiographs. Pediatr Radiol. 1982; 12:175-178.

13. Kravitz H, Driesseng G, Gomberg R et al: Accidental falls from elevated surfaces in infants from birth to one year of age. Pediatrics. 1969; 44:869-872.

14. Helfer RE, Slovis TI, Black M: Injuries resulting when smal children fall out of bed. Pediatrics. 1977; 60:533-535.

15. Merten DF, Osborne DRS, Radkowski MA, Leonidas JC: Craniocerebral trauma in the child abuse syndrome: radiological observations. Pediatr Radiol. 1994; 14:272-277.

16. Gómez de Terreros I, Gómez de Terreros M: Malos tratos infantiles. Aspectos psiconeurológicos. En: Gómez MR, Montilla J, Nieto M. Neurología y neuropsicología pediátrica. Editado Diputación Provincial.Jaén, 1995. pp1519-1549.

17. Jaspan T, Norborouh G, Punt JAG et al : Cerebral contusion fears as a marker of child abuse-detection by cranial sanography. Pediatr Radiol. 1992; 22:237-245.

18. Rubin DM, McMillan C, Helfaer M, Christian C: Edema pulmonar asociado a malos tratos: informes de casos y revisión de los estudios publicados. Pediatrics (ed esp). 200I; 52 (3):179-185. 